\title{
Preparation and physicochemical characterization of omeprazole:methyl-beta-cyclodextrin inclusion complex in solid state
}

\author{
Ana Figueiras · Laura Ribeiro $\cdot$ M. Teresa Vieira \\ Francisco Veiga
}

Received: 15 May 2006/ Accepted: 20 October 2006/ Published online: 20 January 2007

(C) Springer Science+Business Media B.V. 2007

\begin{abstract}
In this work, we illustrate the usefulness of cyclodextrins, namely, methyl- $\beta$-cyclodextrin $(\mathrm{M} \beta \mathrm{CD})$, an amorphous, methylated derivative of the natural $\beta$-cyclodextrin $(\beta \mathrm{CD})$, as a tool to form an inclusion complex with omeprazole (OME), a poorly water soluble drug. Solid binary systems between OME and $\mathrm{M} \beta \mathrm{CD}$ were prepared experimentally in a stoichiometry $1: 1$ by different techniques (physical mixing, kneading, spray-drying and freeze-drying). Afterward these products were characterized by Fourier transform-infrared spectroscopy (FTIR); X-ray diffractometry (XRPD) and scanning electron microscopy (SEM). The results obtained suggest that spray-drying and freeze-drying methods yield a higher degree of amorphous entities suggesting the formation of inclusion complexes between $\mathrm{OME}$ and $\mathrm{M} \beta \mathrm{CD}$.
\end{abstract}

Keywords Inclusion complex · Freeze-drying · Methyl- $\beta$-cyclodextrin · Omeprazole $\cdot$ Spray-drying

\footnotetext{
A. Figueiras $\cdot$ F. Veiga $(\bowtie)$

Laboratory of Pharmaceutical Technology, Faculty of Pharmacy, University of Coimbra, Coimbra 3000-295, Portugal

e-mail: fveiga@ci.uc.pt
}

\section{A. Figueiras - L. Ribeiro · F. Veiga \\ Pharmaceutical Studies Center, Faculty of Pharmacy, University of Coimbra, Coimbra, Portugal}

\section{T. Vieira}

Department of Mechanical Engineering, Faculty of Sciences and Technology, University of Coimbra, Coimbra, Portugal

\section{Introduction}

The ultimate mediator of acid secretion is the $\mathrm{H}^{+} / \mathrm{K}^{+}$ATPase. This pump is unique to the parietal cells and a number of specific inhibitors of it have, therefore, been developed. The available compounds belong to the family of substituted benzimidazoles: omeprazole (OME), lansoprazole, pantoprazole and rabeprazole [1]. In the acid space of the secreting parietal cells these compounds are converted to thiophilic sulfonamide or sulfenic acid which reacts mainly with the Cys- 813 residue in the catalytic subunit of the $\mathrm{H}^{+} / \mathrm{K}^{+}$ATPase, which is critical for enzyme inactivation [2]. OME, the primary member of the proton pump inhibitors, has been extensively used to control acid disorders. However, the main pharmaceutical drawbacks are mainly related to the physicochemical instability to heat, light and acidic media, even with coated formulations. Moreover the low aqueous solubility of OME $\left(\sim 0.4 \%\right.$ at $\left.25{ }^{\circ} \mathrm{C}\right)$ is responsible for small dissolution rates and hence low bioavailability [3]. In recent years, to overcome the drugs stability and solubility limitations, several approaches have been investigated. Cyclodextrins (CDs) have been extensively used as complexing agents to improve solubility and stability of a variety of poorly soluble and labile drugs. Natural CDs have limited water solubility that negatively influences water solubility of the formed complex. To overcome this problem alkyl moiety, such as hydroxyalkyl or methyl, on free hydroxyl groups of $\beta \mathrm{CD}$ were introduced. The complexing ability of $\mathrm{CD}$ derivatives was significantly modified in respect to the parents [4].

Therefore the purpose of this work was to investigate the ability of $\mathrm{M} \beta \mathrm{CD}$ to include $\mathrm{OME}$ and to 
perform the physicochemical characterization of the inclusion complex formed in solid state by Fourier transform-infrared spectroscopy (FTIR), X-ray diffractometry (XRPD) and scanning electron microscopy (SEM).

\section{Materials and methods}

Chemicals

Methyl-beta-cyclodextrin, $\mathrm{M} \beta \mathrm{CD}$ (Lot 768240; MW = 1190 and an average degree of substitution, DS $=0.5$ ) was a gift from Roquette (Lestrem, France) and OME (Lot 18104; MW = 345.42) was kindly donated by Belmac Laboratory, S.A. (Barcelona, Spain). All other chemicals and solvents were of analytical grade.

Preparation of solid binary systems

The preparation of OME:M $\beta \mathrm{CD}$ solid systems was performed in 1:1 molar ratio by kneading, spray-drying and freeze-drying. Physical mixtures were prepared as reference to perform comparative evaluations with solid inclusion complexes.

\section{Physical binary mixture (PM)}

PM was prepared by homogeneous blending in a mortar of previously sieved (63-160 $\mu \mathrm{m}$ sieve granulometric fraction) and weighted $\mathrm{OME}$ and $\mathrm{M} \beta \mathrm{CD}$.

\section{Kneaded binary product (KN)}

$\mathrm{M} \beta \mathrm{CD}$ was wetted in a ceramic mortar with a basic aqueous solution with $\mathrm{pH}$ of $10 \pm 0.1$ until a paste was obtained (about $30 \%$ of the total weight). The required amount of OME was then slowly added and the slurry was kneaded for about $45 \mathrm{~min}$. During this process an appropriate volume of the basic aqueous solution was added in order to maintain a suitable consistency and to avoid OME degradation. The final product was then allowed to equilibrate at room temperature for $48 \mathrm{~h}$ protected from light.

\section{Spray-dried binary product (SD)}

Equimolar amounts of $\mathrm{OME}$ and $\mathrm{M} \beta \mathrm{CD}$ were dissolved in ethanol and basic aqueous solution $(\mathrm{pH}=10 \pm 0.1)$, respectively. Both solutions were mixed and stirred for $24 / 48 \mathrm{~h}$, being the $\mathrm{pH}$ of the solutions adjusted during the process to avoid the possible OME degradation. Solutions were subsequently spray dried in a LabPlant SD-05, under the following conditions: inlet temperature $102{ }^{\circ} \mathrm{C}$, outlet temperature $60-65^{\circ} \mathrm{C}$, flow rate of the solution $400 \mathrm{ml} / \mathrm{h}$, airflow rate $40-50 \mathrm{~m}^{3} / \mathrm{h}$ and atomizing air pressure $1.0-1.1$ bar. [5].

\section{Lyophilized binary product $(L P h)$}

An appropriate amount of $\mathrm{M} \beta \mathrm{CD}$ was dissolved to a basic aqueous solutions $(\mathrm{pH}=10 \pm 0.1)$. After that, OME was added to this solution under stirring, according to the stoichiometry 1:1. The solution stirring was maintained for $24 / 48 \mathrm{~h}$. Furthermore, the resultant clear solution was frozen by immersion in an ethanol-bath at $-50{ }^{\circ} \mathrm{C}$ (Shell Freezer, Labconco, Freezone ${ }^{\circledR}$ model 79490) and then the frozen solution was lyophilized in a freeze-dryer (Lyph-lock 6 apparatus, Labconco) for $72 \mathrm{~h}$.

The obtained powders were sieved (63-160 $\mu \mathrm{m})$ and their drug content was determined by UV assay at $305.5 \mathrm{~nm}$.

X-ray powder diffraction (XRPD)

$\mathrm{X}$-ray powder diffraction patterns of $\mathrm{OME}, \mathrm{M} \beta \mathrm{CD}$ and binary systems (PM and inclusion complexes) were obtained at room temperature with a Philips X'Pert, model PW 3040/00 diffractometer system equipped with $\mathrm{Co}$ as anode material and a graphite monochromator using a voltage of $40 \mathrm{kV}$ and a current of $35 \mathrm{~mA}$. The difractograms were recorded in the $2 \theta$ angle range between 5 and $50^{\circ}$ and the process parameters were set at: scan step size of $0.025(2 \theta)$; scan step time of $1.25 \mathrm{~s}$; and acquisition time of $1 \mathrm{~h}$.

Scanning electron microscopy (SEM)

The surface morphology of the raw materials and binary systems (PM and inclusion complexes) were examined by means of a scanning electron microscope (Jeol, JSM 5310, Tokyo, Japan). The samples were fixed on a brass stub using double-sided tape and then made electrically conductive by coating in vacuum with thin layer of copper. The photographs were taken with a Pentax (model MZ-10) camera at an excitation voltage of $10 \mathrm{KV}$ and magnifications factors of 500 and 3500.

Fourier transform infrared spectroscopy (FTIR)

OME, M $\beta C D, P M$ and inclusion complexes spectra were recorded using a Jasco FT/IR-420 spectrometer associated with an ATR horizontal reflexion (Miracle $^{\mathrm{TM}}$, PIKE Technologies). Spectra acquisitions were per- 
formed directly in powder samples with the application of 16 scans at a resolution of $4 \mathrm{~cm}^{-1}$ over the range 4000 $400 \mathrm{~cm}^{-1}$.

\section{Results}

X-ray powder diffraction (XRPD)

The X-ray powder diffractograms of the pure components (OME and $\mathrm{M} \beta \mathrm{CD}$ ), $\mathrm{PM}$ and inclusion complexes, are shown in Fig. 1 and peak intensities are presented in Table 1. The XRPD patterns of OME revealed several diffraction peaks which are indicative of its crystalline character, while a hollow pattern was recorded for $\mathrm{M} \beta \mathrm{CD}$ which comprove its amorphous state. Comparing the diffraction patterns of pure components with PM it was possible to observe that
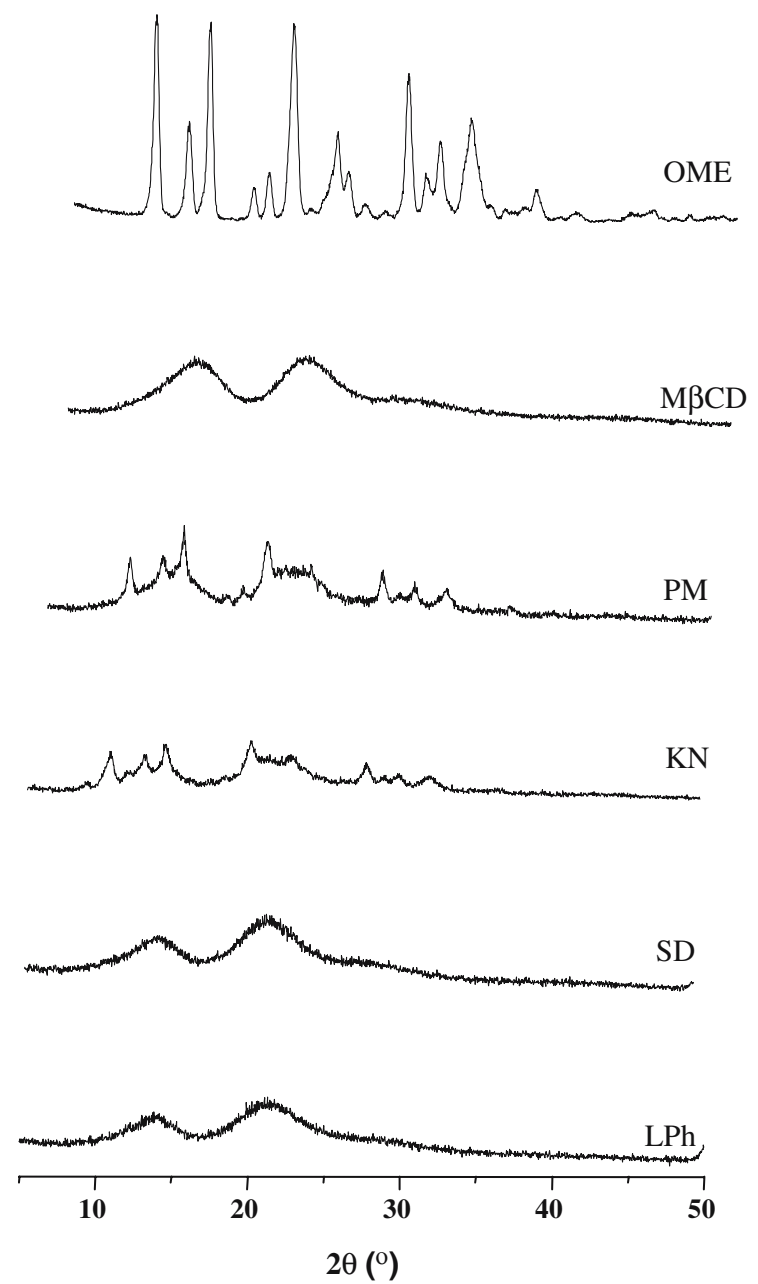

Fig. 1 X-ray diffractograms of OME:M $\beta C D$ inclusion complexes. Omeprazole (OME), methyl-beta-cyclodextrin (M $\beta C D)$, physical mixture (PM), kneaded (KN), spray dried (SD) and lyophilized $(\mathrm{LPh})$ systems diffractograms of PM resulted of the combination of the components analyzed separately, with a marked decrease in the intensity of the diffraction peaks, which can be attributed to the amorphous character of this $\mathrm{CD}$ and the reduction in particle size during the preparation of the PM. The KN system presented a diffraction pattern quite similar to that of PM. However, a lower intensity of it diffraction peaks and overlapping between some OME and $\mathrm{M} \beta \mathrm{CD}$ peaks was also observed. This fact can be explained by the presence of reciprocal interactions in the solid state between host and guest. OME:M $\beta C D$ SD and LPh systems exhibited a complete amorphous character, showing a typical flat behaviour that confirms the strong ability of the amorphous carrier $\mathrm{M} \beta \mathrm{CD}$ to induce drug amorphization [6]. On the other hand, the loss of the crystallinity state can be a consequence of the lyophilization process and because of that X-ray data could not discriminate whether the LPh product obtained was a true inclusion complex or a homogeneous dispersed mixture of the amorphous components [7]. However, in the case of OME:M $\beta \mathrm{CD}$ SD system we could observe a diffraction pattern completely diffuse, which revealed its amorphousness. This behaviour could be attributed to an interaction between OME and $\mathrm{M} \beta \mathrm{CD}$ showing the presence of a new solid phase where a possible formation of an inclusion compound was contemplated [7]. Finally, it was possible to observe that peaks intensities decrease in the following order: $\mathrm{PM}>\mathrm{KN}>\mathrm{SD}>\mathrm{LPh}$ systems corroborating with the results previously report.

\section{Scanning electron microscopy (SEM)}

SEM photomicrographs of OME, $\mathrm{M} \beta \mathrm{CD}$ and OME:M $\beta C D$ systems (PM and inclusion complexes) are reported in Fig. 2. OME is characterized by regular shaped crystals while $\mathrm{M} \beta \mathrm{CD}$ is composed of amorphous spherical particles [8]. OME:M $\beta C D$ PM showed the presence of OME small crystals adhered on the surface of $\mathrm{CD}$ particles. This fact demonstrated the inexistence of apparent interactions between both species in the solid state. In KN product, it was possible to distinguish OME crystals agglomerated on the surface of CD particles that had lost their original shapes and a drastic change in the aspect of $\mathrm{M} \beta \mathrm{CD}$ particles were observed. SD sample showed the typical morphology of preparations generally obtained by this method, very small size spherical particles with high tendency to aggregation [3], which were different from those of raw materials. Finally, LPh product appeared to have a less crystalline structure with a soft, fluffy appearance and again, the crystals of single 
Table 1 Peak intensities of OME in the XRPD patterns of OME-M $\beta$ CD binary systems

\begin{tabular}{llllll}
\hline $2 \theta$ & OME & \multicolumn{4}{l}{ OME:M $\beta$ CD } \\
\cline { 3 - 6 } & & MF & MLX & SD & LPh \\
\hline 12,813 & 1785 & 691 & 669 & 470 & 393 \\
14,288 & 3429 & 842 & 790 & 500 & 417 \\
22,912 & 1608 & 604 & 581 & 556 & 469 \\
27,713 & 2573 & 553 & 538 & 339 & 266 \\
29,838 & 1449 & 408 & 398 & 305 & 269 \\
\hline
\end{tabular}

Omeprazole (OME), methyl-beta-cyclodextrin (M $\beta C D)$, physical mixture (PM), kneaded (KN), spray dried (SD) and lyophilized $(\mathrm{LPh})$ systems

components were still not distinguishable [9]. We can conclude that the changes of KN product when compared with $\mathrm{PM}$ was due to the effect of the preparation method in $\mathrm{M} \beta \mathrm{CD}$ particles and not due to an interaction between both components [10]. On the other hand, the drastic change of the particle shape and aspect in SD and $\mathrm{LPh}$ products, which corroborates the formation of a new solid phase, could be the simple consequence of a crystalline habitus change in those systems or it may support the evidence of the existence of a single phase [5]. Although this technique is not conclusive for assessing the existence of a true inclusion compound in the solid state, it can be useful to prove the homogeneity of the solid phases [3].

\section{Fourier-transform infrared spectroscopy (FTIR)}

The infrared spectra of different samples (OME, $\mathrm{M} \beta \mathrm{CD}, \mathrm{OME}: \mathrm{M} \beta \mathrm{CD} \mathrm{PM}$ and inclusion complexes) are presented in Fig. 3. In FTIR spectra, $\mathrm{C}=\mathrm{C}-\mathrm{N}$ and $\mathrm{S}-\mathrm{C}=\mathrm{N}$ stretching link vibrations $\left(1626.7 \mathrm{~cm}^{-1}\right)$ and Ar-C-O- $\mathrm{CH}_{3}$ vibration $\left(1203.4 \mathrm{~cm}^{-1}\right)$ accompanied by the resonance band at $1075 \mathrm{~cm}^{-1}$ were used to assess the interaction between $\mathrm{M} \beta \mathrm{CD}$ and guest molecule (OME) in the solid state [3]. We can observe that the intensity of both bands is decreased when comparing spectra recorded on the OME:M $\beta \mathrm{CD}$ complexes $(\mathrm{KN}, \mathrm{SD}$ and $\mathrm{LPh}$ ) with those of the PM product. The intensity and amplitude of the shifts verified on these bands were in the following range: $\mathrm{PM}>\mathrm{KN}>\mathrm{SD} \approx \mathrm{LPh}$. In SD and LPh systems, it can be observed that these bands almost disappear, probably owing to a restriction of the vibration related to the complexation process. The band
Fig. 2 Scanning electron microphotographs of omeprazole (A), methyl-betacyclodextrin (B)

OME:M $\beta$ CD physical mixture (C), OME:M $\beta$ CD kneaded (D), lyophilized (E) and spray dried $(\mathbf{F})$ systems
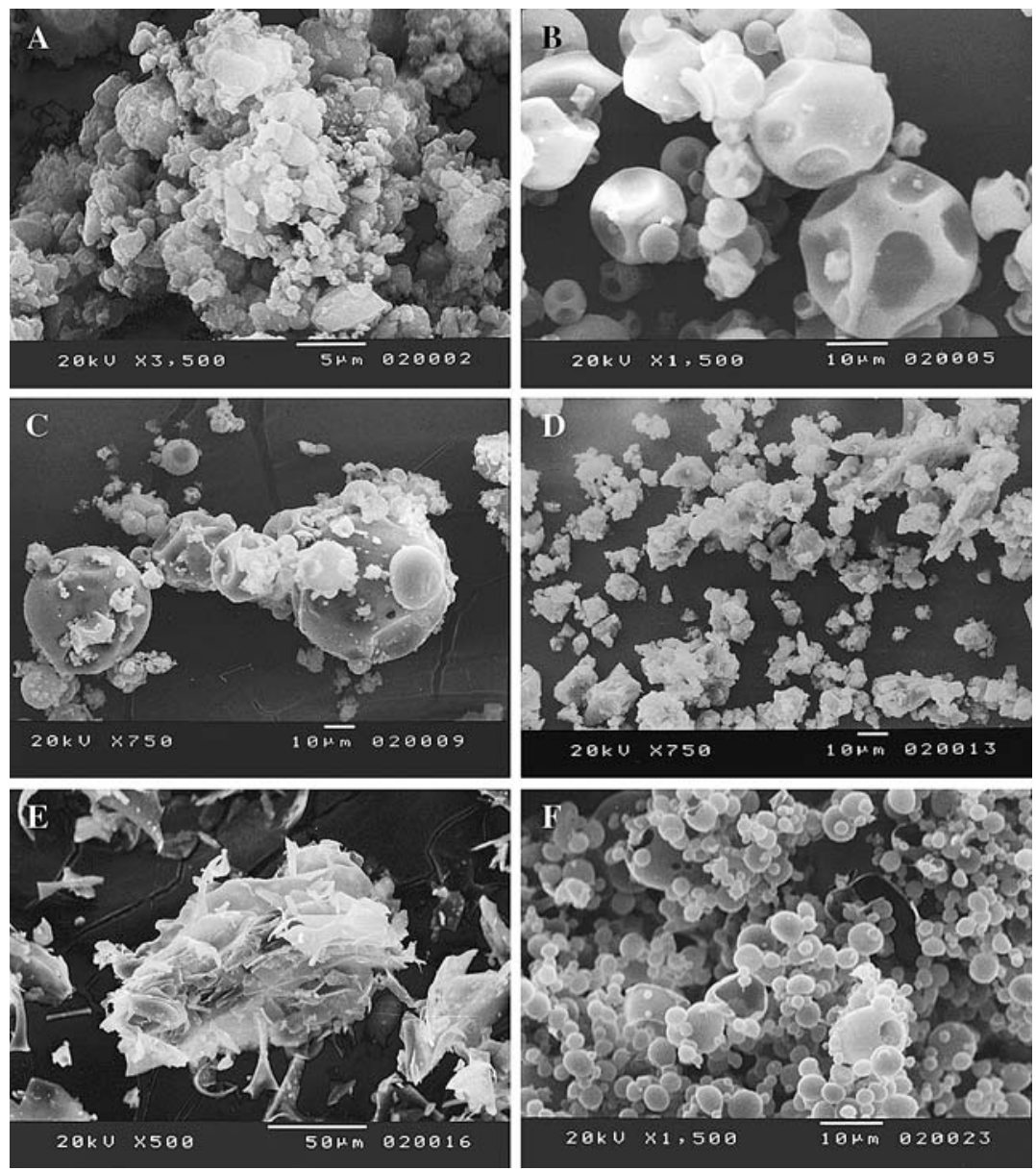


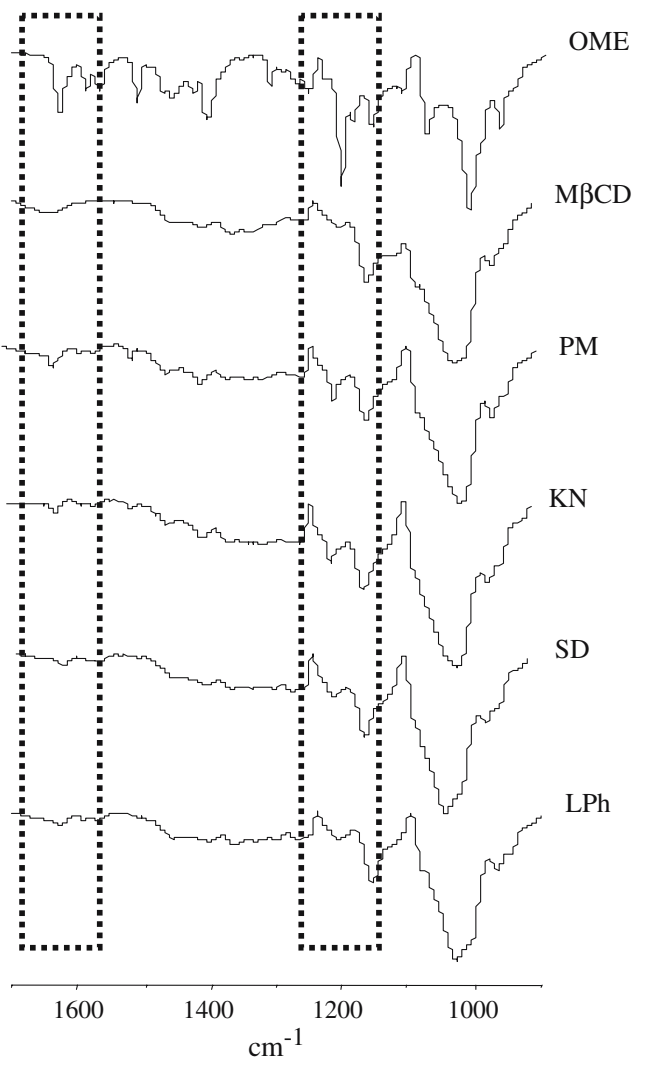

Fig. 3 FTIR spectra (in absorbance) of OME:M $\beta C D$ inclusion complex. Omeprazole (OME), methyl-beta-cyclodextrin $(\mathrm{M} \beta \mathrm{CD})$, physical mixture (PM), kneaded (KN), spray dried (SD) and lyophilized (LPh) systems

positioned at $1203.4 \mathrm{~cm}^{-1}$ is related to bending vibrations of the methoxyl groups of OME and its behaviour may be understood by the occurrence of a restriction due to the inclusion within the cavity of $\mathrm{M} \beta \mathrm{CD}$. These results were also corroborated by ${ }^{1} \mathrm{H}-\mathrm{NMR}$ experiments under publication.

\section{Conclusions}

SEM, FTIR spectroscopy and XRPD diffractometry have been used to study the inclusion complexes formed between $\mathrm{OME}$ and $\mathrm{M} \beta \mathrm{CD}$ in solid phase. Remarkable changes were detected in all characterization methods, indicating the promising formation of new solid phases, some of them in amorphous state, allowing to the conclusion of strong evidences of binary inclusion complex formation between OME and $\mathrm{M} \beta \mathrm{CD}$, particularly for SD and $\mathrm{LPh}$ systems.

Taking in account these results, we can conclude that the interaction of $\mathrm{OME}$ with $\mathrm{M} \beta \mathrm{CD}$, through the formation of an inclusion complex, can lead to important modifications on the physicochemical properties (solubility, stability and consequently bioavailability) of the guest molecule (OME). Those modifications may have a significant impact on the biological effects of the drug. Therefore, studies are being performed to evaluate the potential biopharmaceutical effects of OME:M $\beta C D$ product on a new drug delivery system.

Acknowledgements This work was financially supported by a grant (Praxis SFRH/BD/19175/2004) from FCT (Fundação para a Ciência e a Tecnologia, Portugal). The authors would like to thank assistance of Margarida Henriques by XRPD and SEM acquisitions (Instituto Pedro Nunes, Coimbra), Belmac Laboratory, S.A. (Barcelona, Spain) for the kindly donation of OME and Roquette (Lestrem, France) for their support providing $\beta \mathrm{CD}$ and $\mathrm{M} \beta \mathrm{CD}$.

\section{References}

1. Rosenblatt K.M., Bunjes H., Seeling A., Oelschlãger H.: Investigations on the thermal behavior of omeprazole and other sulfoxides. Pharmazie, 60, 503-507 (2005).

2. Biswas K., Bandypadhyay U., Chattopadhyay I., Varadaraj A., Ali E., Banerjee R.K.: A novel antioxidant and antiapoptotic role of omeprazole to block gastric ulcer through scavenging of hydroxyl radical. Journal of Biological Chemistry. 10993-11001 (2003).

3. Arias M.J., Moyano J.R., Muñoz P., Ginés J.M., Justo A., Giordano F.: Study of omeprazole- $\gamma$ - cyclodextrin complexation in the solid state .Drug Development and Industrial Pharmacy 26, 253-259 (2000).

4. Ventura C.A., Giannone I., Musumeci T., Pignatello R., Ragni L., Landolfi C., Milanese C., Paolino D., Puglisi G.: Physico-chemical characterization of disoxaril dimethyl$\beta$-cyclodextrin inclusion complex and in vitro permeation studies. European Journal of Medicinal Chemistry 41, 233-240 (2006)

5. Ribeiro L.S.S., Ferreira D.C., Veiga F.J.B.: Physicochemical investigation of the effects of water-soluble polymers on vinpocetine complexation with $\beta$-cyclodextrin and its sulfobutyl ether derivative in solution and solid state. European Journal of Pharmaceutical Sciences. 20, 253-266 (2003).

6. Rao V.M., Haslam J.L., Stella V.J.: Controlled and complete release of a model poorly water-soluble drug, prednisolone, from hydroxypropyl methylcellulose matrix tablets using $(\mathrm{SBE})_{7 \mathrm{~m}}-\beta$-cyclodextrin as a solubilizing agent. Journal of Pharmaceutical Sciences. 90, 807-816 (2001).

7. Moyano J.R., Ginés J.M., Arias M.J., Rabasco A.M.: Study of the dissolution characteristics of oxazepam via complexation with $\beta$-cyclodextrin. International Journal of Pharmaceutics. 114, 95-102 (1995).

8. Mura P., Zerrouk N., Faucci M.T., Maestrelli F., Chemtob C.: Comparative study of ibuproxam complexation with amorphous $\beta$-cyclodextrin derivatives in solution and in the solid state. European Journal of Pharmaceutics and Biopharmaceutics. 54, 181-191 (2002).

9. Marzocchi L., Moyano J.R., Muñoz P., Arias M.J., Giordano F.: Current status of ATP-ase proton pump inhibitor complexation with cyclodextrins. Biological Journal of Armenia Special issue: Cyclodextrins. 176-193 (2001).

10. Fernandes C.M., Vieira M.T., Veiga F.J.B.: Physicochemical characterization and in vitro dissolution behavior of nicardipine-cyclodextrin inclusions compounds. European Journal of Pharmaceutical Science. 15, 79-88 (2002). 